\title{
Is early antithrombotic therapy necessary in patients with bioprosthetic aortic valves in normal sinus rhythm?
}

\author{
Andrew W. ElBardissi, MD, MPH, Daniel J. DiBardino, MD, Frederick Y. Chen, MD, PhD, \\ Michael H. Yamashita, MD, and Lawrence H. Cohn, MD
}

\begin{abstract}
Objective: Current American Heart Association/American College of Cardiology guidelines recommend anticoagulation and antiplatelet therapy during the first 90 postoperative days; however, there is wide variability in the administration of antithrombotic therapy after bioprosthetic aortic valve replacement. We sought to determine whether early antithrombotic therapy was necessary in patients undergoing isolated bioprosthetic aortic valve implantation and who were discharged in normal sinus rhythm.
\end{abstract}

\begin{abstract}
Methods: From December 2001 to October 2008, 1131 patients underwent isolated bioprosthetic aortic valve implantation at Brigham and Women's Hospital. After exclusion of patients who underwent concomitant operations $(\mathrm{n}=138,12 \%)$, patients who were anticoagulated preoperatively $(\mathrm{n}=4,0.4 \%)$, and patients who experienced postoperative refractory atrial fibrillation requiring anticoagulation at discharge $(n=128,11 \%)$, our study base consisted of 861 patients. Patients were followed for 90 days postoperatively for the occurrence of thromboembolism, including stroke, transient ischemic attack, or peripheral thromboembolic events and bleeding complications.
\end{abstract}

Results: Of the 861 patients included in this study, 133 (15\%) were anticoagulated with warfarin sodium (AC+) postoperatively and $728(85 \%)$ were not (AC-). Patients who received postoperative anticoagulation were older; had a higher incidence of hypertension, cerebrovascular accident, and pulmonary vascular disease; and were more symptomatic at presentation. The 90-day risk of thromboembolism (cerebrovascular accident, transient ischemic attack, or peripheral thromboembolism) after surgery was $5 \%(\mathrm{n}=6)$ in those who were anticoagulated and $5 \%$ ( $\mathrm{n}=39)$ in those who were not $(P=.67)$. Independent predictors of thromboembolism were found to be increasing age (odds ratio, 1.03; $P=.03$ ), female gender (odds ratio, 2.23; $P=.005$ ), short stature (odds ratio, 0.97; $P=.002$ ), smoking status $(P=.05$ ), New York Heart Association III/IV (odds ratio $1.77, P=.04$ ), and a 19-mm bioprosthetic aortic valve prosthesis (odds ratio, 2.22; $P=.03$ ). Evaluation of each predictor with postoperative acetylsalicylic acid + and $\mathrm{AC}+$ interaction terms revealed that female patients (odds ratio, $0.75 ; P=.03$ AC+; odds ratio, $0.66 ; P=.02$ acetylsalicylic acid+) and patients with a $19-\mathrm{mm}$ bioprosthetic aortic valve (odds ratio, $0.65 ; P=.02 \mathrm{AC}+$; odds ratio, $0.36 ; P=.01$ acetylsalicylic acid + ) had a reduction in the incidence of thromboembolism when administered acetylsalicylic acid or warfarin sodium. Patients who were in New York Heart Association III/IV also had a reduction of thromboembolism when given vitamin $\mathrm{K}$ antagonist (odds ratio, 0.73; $P=.04$ ); a similar trend was observed in patients given acetylsalicylic acid (odds ratio, $0.34 ; P=.06$ ).

Conclusion: Early anticoagulation after isolated bioprosthetic aortic valve replacement in patients in normal sinus rhythm does not seem to reduce the risk of thromboembolism except in high-risk groups. Current recommendations should be revisited, because the only patients who may benefit from anticoagulation are female, those who are highly symptomatic, and those with a small aortic prosthesis. (J Thorac Cardiovasc Surg 2010;139:1137-45)

The use of a bioprosthetic aortic valve (BPAV) is associated with both advantages and disadvantages when compared with the alternative mechanical valve. The durability of a BPAV is limited; however, most patients are protected

\footnotetext{
From the Division of Cardiac Surgery, Brigham and Women's Hospital, Harvard Medical School, Boston, Mass.

Disclosures: None.

Received for publication June 25, 2009; revisions received Sept 7, 2009; accepted for publication Oct 1, 2009; available ahead of print March 22, 2010.

Address for reprints: Lawrence H. Cohn, MD, Division of Cardiac Surgery, Brigham and Women's Hospital, 75 Francis Street, Boston, MA 02115 (E-mail: lcohn@ partners.org)

0022-5223/\$36.00

Copyright (C) 2010 by The American Association for Thoracic Surgery

doi:10.1016/j.jtcvs.2009.10.064
}

from the use of chronic anticoagulation, which may be particularly beneficial to those at high risk of bleeding complications (eg, elderly, fall risk). Although there is a general consensus that long-term anticoagulation with BPAV is unnecessary, there continues to be much debate regarding the necessity of anticoagulation in the immediate postoperative period. The most recent American Heart Association/ American College of Cardiology and European Society of Cardiology recommendations include anticoagulation for 90 days postoperatively with a vitamin $\mathrm{K}$ antagonist (VKA), such as warfarin sodium, and antiplatelet therapy with acetylsalicylic acid (ASA). ${ }^{1-3}$ These recommendations seem to based solely on a single institution study that demonstrated a high incidence of thromboembolism (TE) in the 


$$
\begin{aligned}
& \text { Abbreviations and Acronyms } \\
& \text { ASA }=\text { acetylsalicylic acid } \\
& \text { BPAV }=\text { bioprosthetic aortic valve } \\
& \text { CVA }=\text { cerebrovascular accident } \\
& \text { NYHA }=\text { New York Heart Association } \\
& \text { PPM }=\text { prosthesis-patient mismatch } \\
& \text { TE }=\text { thromboembolism } \\
& \text { TIA }=\text { transient ischemic attack } \\
& \text { VKA }=\text { vitamin K antagonist }
\end{aligned}
$$

first 10 postoperative days in patients who were not anticoagulated. ${ }^{4}$ Notably, these findings were refuted by a more recent study from the same institution that found no difference in the incidence of cerebral ischemic events with regard to the use of postoperative anticoagulation. ${ }^{5}$ Consequently, because of limited and conflicting evidence, there is wide surgeon and institutional variability in the administration of postoperative anticoagulation and antiplatelet therapy after BPAV implantation. ${ }^{6}$ A recent survey of representatives from 48 medical centers in 13 countries found that $43 \%$ of centers routinely prescribe anticoagulation with VKA only, $33 \%$ with ASA only, and $20 \%$ with both ASA and VKA. Four percent of international health care centers routinely administer no antithrombotic therapy after BPAV implantation. ${ }^{6}$

The biologic indication for early postoperative antithrombotic therapy ( 90 postoperative days) after BPAV implantation is to prevent thrombosis of the cloth sewing ring before its endothelialzation. ${ }^{7,8}$ This theoretic indication for thrombotic prophylaxis must be weighed against the risk of bleeding, a potentially fatal complication that occurs with an incidence of $1.5 \%$ to $2.4 \%$ per year ${ }^{9,10}$ and peaks during the initiation of therapy. ${ }^{11}$ Thus, although the scientific community currently lacks appropriately powered randomized trials assessing the need for immediate postoperative anticoagulation in this cohort of patients, it is important that evidence is brought forth evaluating the risks and benefits.

Our institutional practice has also been affected by the lack of certainty in the literature regarding the efficacy and necessity of early antithrombotic therapy after BPAV implantation. Because much of the published evidence includes patients with risk or operative factors (eg, concomitant operations, arrhythmias) that may confound the risk of embolism or decision to anticoagulate, ${ }^{5,12-15}$ we sought to be restrictive by studying only patients who underwent isolated BPAV implantation and were discharged in normal sinus rhythm.

\section{MATERIALS AND METHODS}

From January 8, 2002, to September 29, 2008, 1131 patients underwent BPAV implantation at Brigham and Women's Hospital. After exclusion of patients who underwent concomitant operations ( $\mathrm{n}=138,12 \%)$, who were anticoagulated preoperatively $(n=4,0.4 \%)$, and who experienced postoperative refractory atrial fibrillation requiring anticoagulation at discharge ( $\mathrm{n}=128,11 \%$ ), our study base consisted of 861 patients. On the basis of the variability of our institutional practices, patients were divided into those who were anticoagulated with warfarin $(\mathrm{AC}+)$ and those who were not (AC-). All patients who experienced a stroke in the first 24 postoperative hours were excluded because these events were presumed to have occurred intraoperatively and would not have been affected by postoperative anticoagulation. Similarly, patients who experienced bleeding events in the first 24 postoperative hours were also excluded from the analysis.

All operations were performed by senior attending surgeons at Brigham and Women's Hospital. As a routine, surgeons do not anticoagulate with warfarin or provide antiplatelet therapy; however, given patient-specific risk factors, they may be inclined to do so. Specifically, the indications for anticoagulation in this subset of patients may be widespread but are primarily related to risk factors thought to make the patient at risk of TE (eg, history of cerebrovascular accident [CVA], low ejection fraction) and are made on a case-by-case basis. In these situations, administration of warfarin is established when the patient is hemodynamically and clinically stable, often on the first postoperative day with a goal international normalized ratio of 2.0 to 3.0. Comparatively, surgeons at Brigham and Women's Hospital are more amenable to providing antiplatelet therapy after BPAV replacement. Antiplatelet therapy consists of aspirin $325 \mathrm{mg}$ daily (ASA+) and is initiated when patients are deemed clinically stable and at low risk of major postoperative bleeding events; in most situations, this occurs on postoperative day 1 . Patients were followed and censored at 90 days postoperatively for the composite end point of TE, including the occurrence of CVA, transient ischemic attacks (TIAs), and peripheral TE. An intention-to-treat analysis was performed. Secondary end points consisted of bleeding complications occurring within 90 postoperative days and long-term survival after BPAV implantation. The Brigham and Women's Institutional Review Board approved this study.

\section{Statistical Analysis}

Demographic and other patient-related data were obtained from Brigham and Women's Hospital medical records. Follow-up information was obtained from subsequent clinic visits, written correspondence from local physicians, mailed questionnaires, or direct phone contact with patients or families. Continuous variables are expressed as a mean \pm standard deviation. Student $t$ tests and Pearson's chi-square tests were used to analyze continuous and categoric variables, respectively. The primary end point consisted of a composite outcome of TE, including CVA, TIA, and peripheral TE through the first 90 postoperative days. A post hoc power calculation was performed to assess the effectiveness of this study to detect a reduction of TE using the following parameters: a postoperative TE risk of $6 \%$ (AC-) and $2 \%(\mathrm{AC}+)$ based on a 1 -sided alpha of 0.05 . As demonstrated in Figure 1 , this study exhibited moderate power $(b=0.67)$ to assess an absolute reduction of $4 \%$ in the incidence of TE.

On the basis of the practice patterns of our group, it was hypothesized that the characteristics and profile of patients would differ between $\mathrm{AC}+$ and $\mathrm{AC}-$. Thus, to minimize treatment bias, a multivariate propensity score model was used to create 2 risk-equal groups. All primary and secondary end points were evaluated by adjusting for the propensity to receive anticoagulation. A time-censored Kaplan-Meier cumulative incidence analysis was performed to assess the incidence and distribution of TE between $\mathrm{AC}+$ and $\mathrm{AC}-$. All clinically relevant candidate covariates were evaluated using logistic regression to determine significant univariate predictors of TE. Interaction-term logistic regression models were subsequently created to evaluate the efficacy of anticoagulation in high-risk patients identified in the previous step.

Secondary end points consisted of bleeding events occurring within the first 90 postoperative days (requiring rehospitalization or medical intervention) and long-term survival after BPAV implantation. To analyze survival 


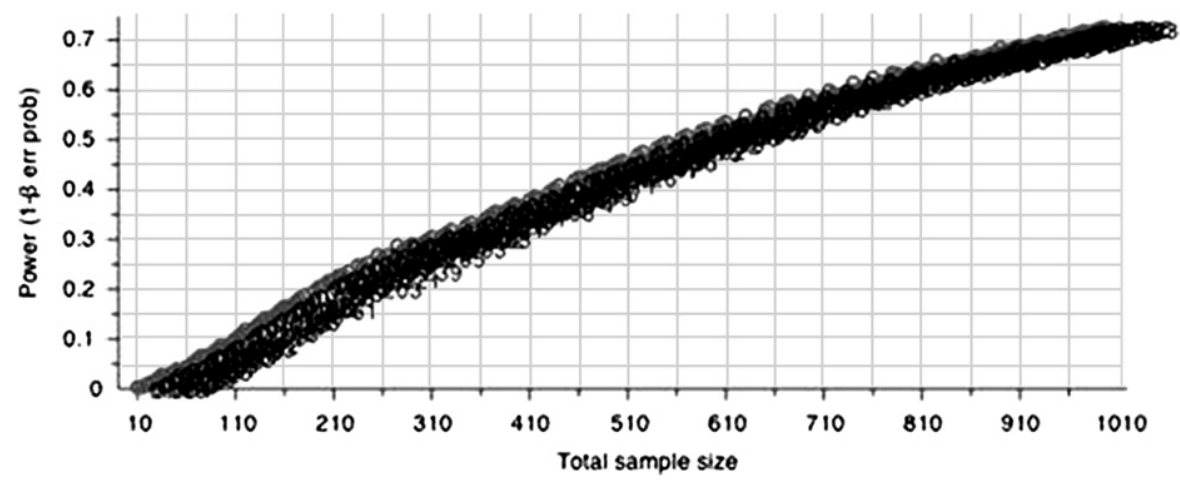

FIGURE 1. Study power versus total sample size based on study parameters.

after valve implantation, a Cox proportional hazards model was used to compare the hazard ratios between the various methods of anticoagulation. By using a baseline survival function estimate derived from the KalbfleischPrentice estimator ${ }^{16}$ (pages 114-118), the effect of antithrombotic therapy on survival was assessed after propensity adjusting in all groups found to be high risk. SAS version 9.1 and JMP version 8.0 (both from SAS Institute Inc, Cary, NC) were used for statistical analysis.

\section{RESULTS}

Table 1 demonstrates preoperative, hemodynamic, and operative data between patients who were anticoagulated $(\mathrm{AC}+)$ and those who were not (AC-). Patients electively anticoagulated were older, had a higher incidence of hypertension, had a previous CVA, and were more symptomatic preoperatively. Furthermore, mean left ventricular ejection fractions were lower and there were increased preoperative mean aortic gradients in instances of aortic stenosis. Of note, there was no difference in the administration of postoperative ASA among those who were given postoperative anticoagulation (AC-; 53\% $[\mathrm{n}=387]$ vs $\mathrm{AC}+; 53 \%[\mathrm{n}=71]$; $P=.96)$. Although all other clinical characteristics were similar between groups, these significant variations that likely affected the decision to anticoagulate could not be excluded as confounders in the occurrence of TE. As such, a 1:2 propensity model was created from the original cohort to validate all study end points. As shown in Table 2, there was no significant variation in clinical characteristics between $\mathrm{AC}+$ and $\mathrm{AC}$ - in the propensity-matched data set.

All patients had complete 90-day postoperative followup. After exclusion of neurologic events occurring within the first 24 hours postoperatively $(n=9)$, the incidence of CVA, TIA, and peripheral TE was $5 \%(\mathrm{n}=6)$ in $\mathrm{AC}+$ and $5 \%(\mathrm{n}=39)$ in $\mathrm{AC}-(P=.67)$ groups. The overall incidence of embolic events was validated with the propensitymatched group $(\mathrm{AC}+; \mathrm{n}=6,5 \%$ vs $\mathrm{AC}-; \mathrm{n}=15,7 \%$, $P=.62)$. There was no difference in the incidence of TE based on the use of postoperative ASA (ASA+; $\mathrm{n}=26$, $6 \%$, vs ASA-; $\mathrm{n}=19,5 \%, P=.57$ ); this finding was consistent after propensity adjusting (ASA $+\mathrm{n}=17,6 \%$ vs ASA-; $\mathrm{n}=4,8 \%, P=.61)$. A time-censored cumulative incidence analysis was performed (Figure 2) and indicated that the majority of events in both groups occurred between postoperative days 2 and 20. After adjusting for the propensity to provide anticoagulation, there continued to be no significant difference in the distribution or freedom from TE between $\mathrm{AC}+$ and $\mathrm{AC}-$ (hazard ratio, $1.41 ; P=.45$ ) or between ASA+ and ASA- (hazard ratio, 1.44; $P=.38$ ).

Univariate predictors of TE are shown in Table 3; age, female gender, short stature, smoking status, severe symptomatology (New York Heart Association [NYHA] III/IV), and a 19-mm prosthesis were found to increase the likelihood of TE. Because of the small number of TE events, a multivariate model with high statistical validity was unable to be created; however, covariate correlations were found to be highly significant. Of the 95 patients who had $19-\mathrm{mm}$ aortic valves implanted, $89(94 \%)$ were female $\left(\chi^{2}=112, P<.0001\right)$. Furthermore, female patients were older $(72.44 \pm 11.4$ years vs $68.0 \pm 13.5$ years, $P<.0001)$, more likely to be in NYHA III/IV ( $\mathrm{n}=164,44 \%$ vs $\mathrm{n}=143,29 \%, \chi^{2}=P<.0001$ ), more likely to be shorter compared with their male counterparts $(160.19 \pm 7.4 \mathrm{~cm}$ vs $175.72 \pm 8.89 \mathrm{~cm}, P<.0001)$, and less likely to be smokers $(\mathrm{n}=234,52 \%$ vs $\mathrm{n}=136$, $33 \%, P<.0001)$.

To investigate whether antithrombotic therapy affected the occurrence of TE in these high-risk groups, logistic regression interaction terms were created with each univariate predictor and each method of antithrombotic therapy (ASA and warfarin). As shown in Table 4, the use of either ASA or VKA postoperatively decreased the risk of TE in female patients and those with a 19-mm BPAV. Furthermore, patients in NYHA III/IV who were anticoagulated with VKA had a lower incidence of TE in the postoperative period compared with those in NYHA III/IV who were not; this trend was also appreciated in patients who were given ASA postoperatively $(P=.06)$.

There was no significant increase in the incidence of bleeding at 90 days in patients who were anticoagulated postoperatively $(\mathrm{AC}+; \mathrm{n}=6,4.6 \%$ vs $\mathrm{AC}-; \mathrm{n}=20$, $2.8 \%, P=.29)$. This finding was consistent in the propensity-matched cohort $(\mathrm{AC}+\mathrm{n}=6,5 \%, \mathrm{AC}-\mathrm{n}=8,3.5 \%$, $P=.44)$. 
TABLE 1. Demographic, hemodynamic, and operative patient characteristics of total cohort

\begin{tabular}{|c|c|c|c|}
\hline \multicolumn{4}{|c|}{ Complete cohort } \\
\hline & $\begin{array}{c}\text { Postoperative } \\
\text { anticoagulation } \\
(\mathbf{n}=\mathbf{1 3 3}) \\
\end{array}$ & $\begin{array}{c}\text { No postoperative } \\
\text { anticoagulation } \\
(\mathbf{n}=728)\end{array}$ & $\begin{array}{c}P \\
\text { value }\end{array}$ \\
\hline Age & $74.54 \pm 9.1$ & $68.95 \pm 13.1$ & $<.000$ \\
\hline Weight (kg) & $79 \pm 19$ & $80 \pm 18$ & .48 \\
\hline Height $(\mathrm{cm})$ & $168 \pm 10.8$ & $169.21 \pm 10.8$ & .44 \\
\hline Smoking history, n (\%) & $65(49 \%)$ & $348(48 \%)$ & .82 \\
\hline Hypertension, n (\%) & $109(81 \%)$ & $452(62 \%)$ & $<.000$ \\
\hline Diabetes, n (\%) & $24(18 \%)$ & $121(17 \%)$ & .68 \\
\hline Hyperlipidemia, n (\%) & $92(69 \%)$ & $440(60 \%)$ & .06 \\
\hline Baseline creatinine & $1.29 \pm 1.36$ & $1.08 \pm 0.6$ & .07 \\
\hline Renal failure, n (\%) & $11(8 \%)$ & $30(4 \%)$ & .04 \\
\hline History of CVA, n (\%) & $14(6 \%)$ & $24(3 \%)$ & .02 \\
\hline $\begin{array}{l}\text { Peripheral vascular } \\
\text { disease, } \mathrm{n}(\%)\end{array}$ & $19(14 \%)$ & $76(10 \%)$ & .19 \\
\hline $\begin{array}{l}\text { Cerebrovascular disease, } \\
\mathrm{n}(\%)\end{array}$ & $29(13 \%)$ & $83(11 \%)$ & .29 \\
\hline \multicolumn{3}{|l|}{ NYHA functional status } & .000 \\
\hline I & $20(15 \%)$ & $161(22 \%)$ & \\
\hline II & $44(33 \%)$ & $330(45 \%)$ & \\
\hline III & $60(45 \%)$ & $214(29 \%)$ & \\
\hline IV & $9(7 \%)$ & $23(3 \%)$ & \\
\hline \multicolumn{4}{|l|}{$\begin{array}{l}\text { Previous surgical } \\
\text { interventions }\end{array}$} \\
\hline Previous CABG, n (\%) & $18(14 \%)$ & $76(10 \%)$ & .29 \\
\hline $\begin{array}{l}\text { Previous valve } \\
\quad \text { procedures, } \mathrm{n}(\%)\end{array}$ & 0 & 0 & \\
\hline \multicolumn{4}{|l|}{ Echocardiographic data } \\
\hline Ejection fraction & $54 \pm 13$ & $58 \pm 11$ & .007 \\
\hline Mean PAP & $28 \pm 12$ & $25 \pm 12$ & .26 \\
\hline Aortic gradient & $44 \pm 20$ & $48 \pm 18$ & .04 \\
\hline $\begin{array}{l}\text { Moderate or greater aortic } \\
\text { regurgitation }\end{array}$ & $65(49 \%)$ & $343(47 \%)$ & .7 \\
\hline \multicolumn{4}{|l|}{ Operative characteristics } \\
\hline CPB time (min) & $125 \pm 59$ & $111 \pm 53$ & .02 \\
\hline Crossclamp time & $80 \pm 36$ & $75 \pm 36$ & .77 \\
\hline Prosthesis size & $23(21-25)$ & $23(21-25)$ & .07 \\
\hline
\end{tabular}

$C V A$, Cerebrovascular accident; $N Y H A$, New York Heart Association; $C A B G$, coronary artery bypass grafting; $P A P$, pulmonary artery pressure; $C P B$, cardiopulmonary bypass.

Long-term follow-up was available for 855 patients $(99 \%)$ at a mean of $3.82 \pm 2.22$ years. After propensity adjusting, the use of ASA (Figure 3,A) or VKA (Figure 3, B) did not seem to influence survival. All high-risk groups (Table 3) were evaluated on the basis of method of anticoagulation (ASA Figure 3, $C, E, G$; VKA Figure 3, $D, F, H$ ); there were no significant differences in survival based on the method of anticoagulation in these subsets.

\section{DISCUSSION}

The present study was designed to detect whether postoperative antithrombotic therapy with warfarin or ASA in the first 90 postoperative days is protective against the occur-
TABLE 2. Propensity-matched cohort demographic and operative patient characteristics

\begin{tabular}{|c|c|c|c|}
\hline \multicolumn{4}{|c|}{ Propensity-matched cohort } \\
\hline &  & $\begin{array}{c}\text { No postoperative } \\
\text { anticoagulation } \\
(\mathbf{n}=\mathbf{2 3 2}) \\
\end{array}$ & $\begin{array}{c}P \\
\text { value } \\
\end{array}$ \\
\hline Age (y) & $75.14 \pm 8.83$ & $74.97 \pm 9.07$ & .87 \\
\hline Weight $(\mathrm{kg})$ & $79.92 \pm 17.65$ & $78.89 \pm 16.18$ & .76 \\
\hline Height $(\mathrm{cm})$ & $168.45 \pm 10.76$ & $166.92 \pm 12.36$ & .26 \\
\hline Smoking history, n (\%) & $56(48 \%)$ & $116(50 \%)$ & .76 \\
\hline Hypertension, $\mathrm{n}(\%)$ & $95(82 \%)$ & $194(84 \%)$ & .69 \\
\hline Diabetes, $\mathrm{n}(\%)$ & $22(19 \%)$ & $53(23 \%)$ & .41 \\
\hline Hyperlipidemia, n (\%) & $82(71 \%)$ & $156(67 \%)$ & .51 \\
\hline Baseline creatinine & $1.21 \pm 0.81$ & $1.12 \pm 0.61$ & .3 \\
\hline Renal failure, n (\%) & $9(8 \%)$ & $13(6 \%)$ & .44 \\
\hline History of CVA, n (\%) & $7(6 \%)$ & $8(4 \%)$ & .26 \\
\hline $\begin{array}{l}\text { Peripheral vascular } \\
\text { disease, } \mathrm{n}(\%)\end{array}$ & $20(17 \%)$ & $40(17 \%)$ & .99 \\
\hline $\begin{array}{l}\text { Cerebrovascular disease, } \\
\mathrm{n}(\%)\end{array}$ & $17(15 \%)$ & $31(13 \%)$ & .74 \\
\hline \multicolumn{4}{|l|}{ NYHA functional status } \\
\hline I & $91(16 \%)$ & $44(19 \%)$ & .91 \\
\hline II & $43(37 \%)$ & $87(38 \%)$ & \\
\hline III & $50(43 \%)$ & $92(40 \%)$ & \\
\hline IV & $4(3 \%)$ & $9(4 \%)$ & \\
\hline \multicolumn{4}{|l|}{$\begin{array}{l}\text { Previous surgical } \\
\text { interventions }\end{array}$} \\
\hline Previous CABG, n (\%) & $14(12 \%)$ & $31(13 \%)$ & \\
\hline $\begin{array}{l}\text { Previous valve } \\
\text { procedures, } \mathrm{n}(\%)\end{array}$ & 0 & 0 & \\
\hline \multicolumn{4}{|l|}{ Echocardiographic data } \\
\hline Ejection fraction & $55.44 \pm 12.47$ & $57.92 \pm 10.83$ & .07 \\
\hline Mean PAP & $27.92 \pm 11.92$ & $26.67 \pm 10.26$ & .66 \\
\hline Aortic stenosis & $101(87 \%)$ & $206(89 \%)$ & .64 \\
\hline Aortic gradient & $50.94 \pm 19.64$ & $49.26 \pm 18.44$ & .48 \\
\hline $\begin{array}{l}\text { Moderate or greater } \\
\text { aortic regurgitation }\end{array}$ & $61(53 \%)$ & $108(47 \%)$ & .29 \\
\hline \multicolumn{4}{|l|}{ Operative characteristics } \\
\hline CPB time (min) & $123.37 \pm 57.65$ & $114.2 \pm 57.84$ & .16 \\
\hline Crossclamp time & $79.35 \pm 33.58$ & $76.95 \pm 39.16$ & .57 \\
\hline Prosthesis size & $23(21-25)$ & $23(21-25)$ & .07 \\
\hline
\end{tabular}

$C V A$, Cerebrovascular accident; NYHA, New York Heart Association; $C A B G$, coronary artery bypass grafting; $P A P$, pulmonary artery pressure; $C P B$, cardiopulmonary bypass.

rence of TE. The overall incidence of TE in patients who underwent isolated BPAV discharged in normal sinus rhythm was low and did not differ on the basis of the type or lack of antithrombotic therapy. These results are in stark contrast with a previous study ${ }^{4}$ that observed an extremely high rate of TE in patients who were not anticoagulated with intravenous low-molecular-weight heparin and VKA. Although this discrepancy is not easily explained, it is reassuring that subsequent studies have found that providing antithrombotic therapy for the first 90 postoperative days provides no appreciable reduction in the incidence of TE. ${ }^{5,13,15}$ Despite this evidence, however, many medical and surgical societies 


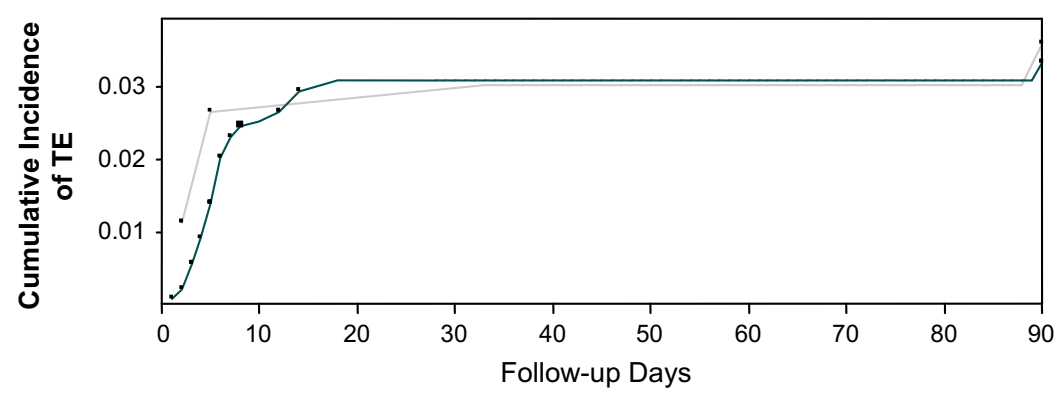

FIGURE 2. Cumulative incidence analysis (composite of stroke, TIA, and peripheral thromboemboli). TE, Thromboembolism.

(eg, American Heart Association/American College of Cardiology, ${ }^{2}$ American College of Clinical Pharmacy, ${ }^{17}$ European Society of Cardiology ${ }^{17}$ ) have taken the conservative approach $^{6}$ and continue to recommend antithrombotic therapy. This study examined a highly select group of patients (isolated BPAV in normal sinus rhythm at discharge) and rigorously adjusted for potential confounders of TE to hone into the causal association between BPAV and TE. As such, this study emphasizes that the use of VKA or ASA is not indicated for widespread use in patients undergoing BPAV implantation.

As is the case with the current analysis, most studies examining the necessity of VKA or ASA prophylaxis after BPAV implantation have been retrospective and are limited by selection bias. ${ }^{4,5,11,15,18,19}$ Comparatively, the few prospective studies performed have been grossly underpowered, ${ }^{13,20}$ and thus do not provide adequate evidence to justify any practicechanging conclusions. Despite this lack of level I evidence, many studies have observed similar trends with regard to the use of early anticoagulation. In one of the largest series to date, Sundt and colleagues ${ }^{5}$ did not find a decrease in the risk of cerebral ischemic events in patients anticoagulated after BPAV implantation. In a similarly designed study, Moinuddeen and colleagues ${ }^{15}$ also failed to appreciate a reduction in cerebral ischemic events in patients who were administered low-molecular-weight heparin + VKA versus those given no anticoagulation. Others have studied the risk of TE in patients administered antiplatelet agents versus low-molecular-weight heparin +VKA and have also found no reduction in the incidence of TE. ${ }^{11,19}$ Notably, despite failing to reduce the incidence of TE events, early anticoagu-

TABLE 3. Univariate predictors of thromboembolism

\begin{tabular}{ll}
\hline \multicolumn{2}{c}{ Univariate predictors of thromboembolism } \\
\hline \multicolumn{1}{c}{ Covariate } & \multicolumn{1}{c}{ Odds ratio } \\
\hline Age & $1.03(1.003-1.05)$ \\
Female gender & $2.23(1.27-3.93)$ \\
Height $(\mathrm{cm})$ & $0.96(0.94-0.98)$ \\
Smoking history & $1.77(1-3.16)$ \\
NYHA III/IV & $1.77(1.01-3.07)$ \\
19-mm BPAV prosthesis & $2.22(1.10-4.46)$ \\
\hline
\end{tabular}

NYHA, New York Heart Association; $B P A V$, bioprosthetic aortic valve. lation in this group of patients has never been shown to increase the risk of bleeding events, a finding that is reaffirmed with the present study. Although it seems that this study merely confirms the findings of previous reports, there are important differences between our study design and those that have predated it. First, we excluded all patients undergoing concomitant procedures and those requiring antithrombotic therapy. We also included all ischemic events, including CVAs, TIAs, and peripheral embolic events, thereby explaining why the incidence of TE in our study $(5 \%)$ is higher than previously reported $\left(\sim 2 \%^{5,15,18}\right)$. Finally, to minimize treatment bias, we used multivariate propensity analysis. We believe these modifications to the study design allowed us to more accurately investigate the association between BPAV and TE and the potential mitigation that might occur as the result of antithrombotic therapy. Although the conclusion that widespread early anticoagulation offers minimal benefit is consistent with previous studies, our restrictive inclusion criteria and study design allowed us to identify trends that more clearly define the role of antithrombotic therapy after BPAV implantation.

Consistent with other analyses, our univariate analysis identified that increasing age ${ }^{18}$ and smoking history ${ }^{11}$ are independent predictors of TE. We also identified a number of variables that have not been implicated, such as female gender, short stature, severe symptomatology (NYHA III/IV), and implantation of a 19-mm aortic BPAV. The association between TE and depressed left ventricular function has been described ${ }^{18}$ and may explain the observed finding that patients in NYHA III/IV experienced postoperative TE at a higher rate than those who were minimally symptomatic. The other covariates implicated in this study (female gender, small stature, and 19-mm prosthesis) have not been described and bring into the question the physiologic and biochemical phenomena at work. In an effort to build a multivariate model, it became evident that we would be unable to do so with statistical robustness because of the high level of intercovariate correlation. For example, nearly all 19-mm prostheses were used in female patients. Also, female patients were shorter, older, less frequently smokers, and more likely to be in preoperative NYHA III/IV. Consequently, we do not believe all univariate predictors are 
TABLE 4. Mitigation of postoperative thromboembolus in high-risk patient groups

\begin{tabular}{lccc}
\hline & AC $+($ vs AC -$)$ & $\boldsymbol{P}$ value & ASA $+(\mathbf{v s}$ ASA-) \\
\hline Age & $0.99(0.99-1.00)$ & .14 & $1.005(0.998-1.013)$ \\
Female gender & $0.75(0.58-0.97)$ & .03 & $0.66(0.46-0.93)$ \\
Height $(\mathrm{cm})$ & $1.002(0.99-1.006)$ & .22 & $0.99(0.996-1.002)$ \\
Smoking history & $0.79(0.61-1.03)$ & .08 & $1.27(0.92-1.77)$ \\
NYHA III/IV & $0.73(0.55-0.98)$ & .04 & $0.34(0.10-1.07)$ \\
19-mm BAV prosthesis & $0.65(0.45-0.93)$ & .02 & $0.36(0.16-0.81)$ \\
\hline
\end{tabular}

$A S A$, Acetylsalicylic acid; $N Y H A$, New York Heart Association; $B A V$, bioprosthetic aortic valve.

causally related to the occurrence of TE. These trends are concerning, however, and warrant further investigation, and should be taken into account when making a decision about providing early postoperative antithrombotic therapy.

Thrombi consist of thin fibrin strands and platelet aggregate $^{21}$ that occur primarily on the BPAV cloth sewing ring before endothelialzation. ${ }^{7,8}$ Primary factors facilitating the formation of thrombi in the context of BPAV implantation include high laminar blood flow ${ }^{22}$ and a thrombogenic surface. Although not universally true, patients with $19-\mathrm{mm}$ valves are those most likely to experience high orifice blood flow as the result of narrow valve dimensions; thus, theoretically, they are highly susceptible to thrombi formation.

Notably, there is a wide body of literature describing prosthesis-patient mismatch (PPM); the general consensus being that severe PPM in patients undergoing BAV implantation negatively affects long-term survival. ${ }^{23-25}$ Although PPM was not specifically addressed in this study, Tasca and colleagues ${ }^{26}$ previously found that more than $90 \%$ of patients with a 19-mm BAV have the most severe form of PPM. Investigators have not studied the role of PPM in postoperative TE; however, it is curious that female patients, those with 19-mm valves, and patients with short stature had a significantly higher risk of postoperative TE. We can only speculate that PPM is causally related to this finding but do believe valve size and particularly PPM (a variable linking 2 of our univariate predictors) are important to consider when deciding to provide early postoperative anticoagulation after BPAV implantation.

Because of the variety of practices at Brigham and Women's Hospital, we were able to retrospectively examine whether antithrombotic therapy affected the occurrence of TE in the high-risk groups we identified (Table 3). By creating interaction logistic regression models with each method of antithrombotic therapy, we found that certain groups of patients may have benefited by some form of antithrombotic therapy. Female patients who were given warfarin and those who were given ASA postoperatively had a lower risk of TE compared with female patients who were not given antithrombotic therapy. Furthermore, patients with a $19-\mathrm{mm}$ BPAV were also protected from TE when provided warfarin or ASA postoperatively. The final subset of patients who were offered TE protection were those in NYHA III/IV; these patients achieved a $35 \%$ to $65 \%$ relative reduction in the incidence of TE when given either warfarin or ASA. In summary, these findings suggest that TE may be significantly affected by BPAV prosthesis size and preoperative cardiovascular function. Thus, strong consideration of immediate antithrombotic therapy should be given to these subsets of patients.

\section{LIMITATIONS}

All retrospective studies have inherent limitations, such as treatment bias and confounding, that can merely be addressed but not completely eradicated. We believe we have eliminated confounders by restricting our cohort to those undergoing isolated BPAV who were discharged in normal sinus rhythm. ${ }^{18}$ After examining the differences in characteristics between $\mathrm{AC}+$ and $\mathrm{AC}-$, it was evident that treatment bias was certainly a limitation and would affect interpretability of this study. As such, we used a multivariate propensity analysis to account for this bias. Despite these manipulations, we were still able to attain moderate power in our ability to detect a significant difference in the incidence of early postoperative TE. Unfortunately, this study was not designed or powered to assess the optimal method of antithrombotic therapy. Our analyses did, however, allow us to identify high-risk groups who may benefit from antithrombotic therapy and provide important data for future prospective randomized investigations. Although these results should be analyzed with scrutiny, we maintain that because of our study design and end points of interest, this report brings to light information that has not previously been described and is critically important to the postoperative treatment of patients undergoing BPAV implantation.

\section{CONCLUSION}

Early antithrombotic therapy after BPAV remains a controversial topic highlighted by a high degree of institutional and surgeon variability. The majority of medical societies continue to recommend antithrombotic therapy for 90 postoperative days; however, this recommendation seems to be based on reports with conflicting results and significant limitations. On the basis of our findings, postoperative antithrombotic therapy should be considered for patients at high risk of TE, including female patients, those with a small aortic prosthesis, and those who are severely symptomatic preoperatively. The risk of TE that is reduced in high-risk patients is 

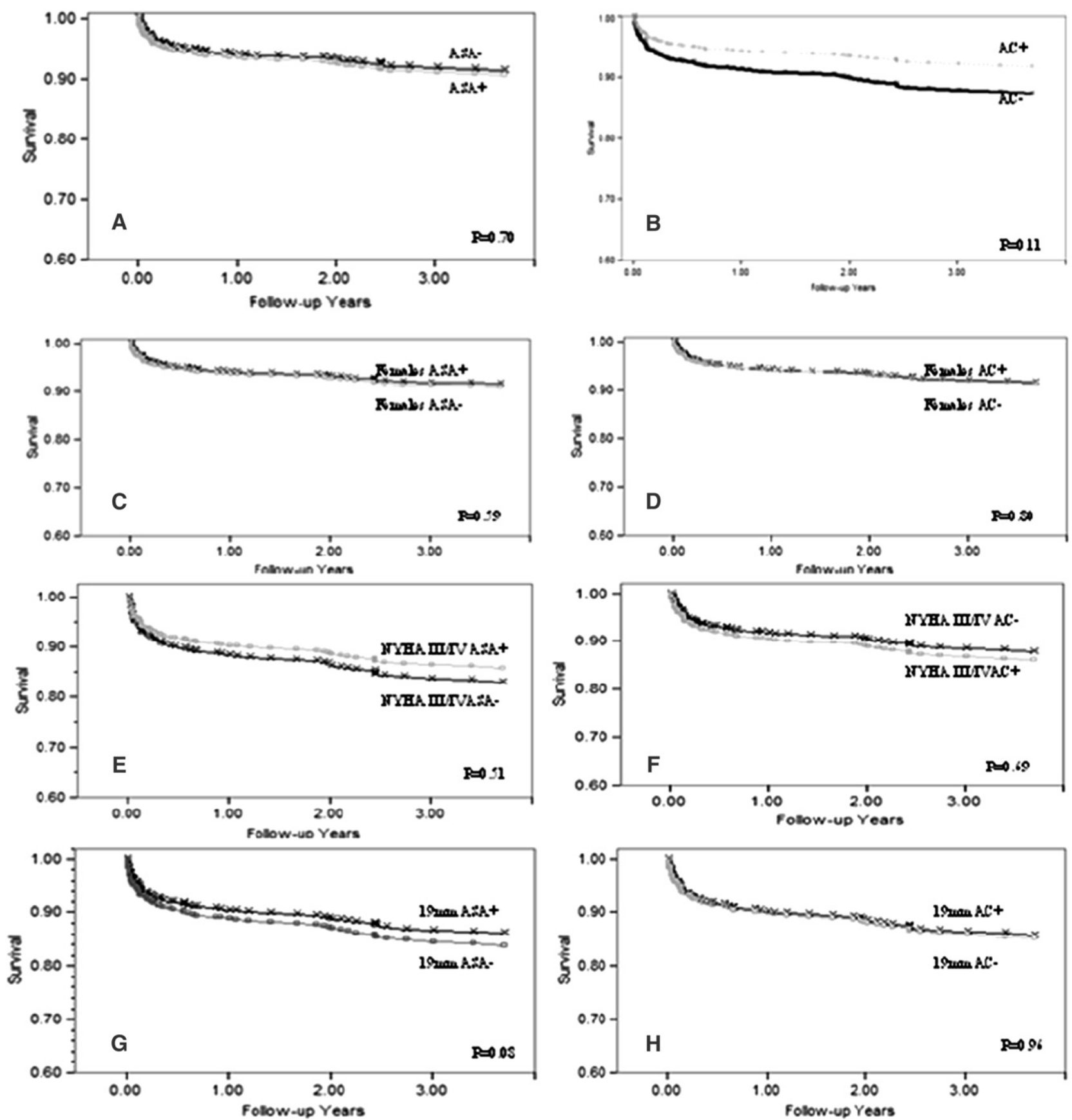

FIGURE 3. Long-term survival using the Cox proportional hazard approximation. ASA, Acetylsalicylic acid; NYHA, New York Heart Association.

likely secondary to prevention of thrombus formation in high-flow circumstances (19-mm BPAV) and depressed cardiac function (NYHA III/IV). Unfortunately, the mode of antithrombotic therapy that offers optimal prevention while minimizing bleeding risks remains unclear. Future prospective randomized studies will be necessary to investigate the role of antithrombotic therapy to develop evidence-based recommendations of the highest statistical certainty.

\section{References}

1. Carabello BA. What is new in the 2006 ACC/AHA guidelines on valvular heart disease? Curr Cardiol Rep. 2008;10:85-90.

2. Bonow RO, Carabello BA, Chatterjee K, de Leon AC Jr, Faxon DP, Freed MD, et al. ACC/AHA 2006 guidelines for the management of patients with valvular heart disease: a report of the American College of Cardiology/ American Heart Association Task Force on Practice Guidelines (writing Committee to Revise the 1998 guidelines for the management of patients with valvular heart disease) developed in collaboration with the Society of Cardiovascular Anesthesiologists endorsed by the Society for Cardiovascular 
Angiography and Interventions and the Society of Thoracic Surgeons. $J$ Am Coll Cardiol. 2006;48:e1-148.

3. Vahanian A, Baumgartner H, Bax J, Butchart E, Dion R, Filippatos G, et al. Guidelines on the management of valvular heart disease: The Task Force on the Management of Valvular Heart Disease of the European Society of Cardiology. Eur Heart J. 2007;28:230-68.

4. Heras M, Chesebro JH, Fuster V, Penny WJ, Grill DE, Bailey KR, et al. High risk of thromboemboli early after bioprosthetic cardiac valve replacement. $J$ Am Coll Cardiol. 1995;25:1111-9.

5. Sundt TM, Zehr KJ, Dearani JA, Daly RC, Mullany CJ, McGregor CG, et al. Is early anticoagulation with warfarin necessary after bioprosthetic aortic valve replacement? J Thorac Cardiovasc Surg. 2005;129:1024-31.

6. Colli A, Verhoye JP, Heijmen R, Strauch JT, Hyde JA, Pagano D, et al. Antithrombotic therapy after bioprosthetic aortic valve replacement: ACTION Registry survey results. Eur J Cardiothorac Surg. 2008;33:531-6.

7. Stein B, Fuster V, Halperin JL, Chesebro JH. Antithrombotic therapy in cardiac disease. An emerging approach based on pathogenesis and risk. Circulation. 1989;80:1501-13.

8. Chesebro JH, Adams PC, Fuster V. Antithrombotic therapy in patients with valvular heart disease and prosthetic heart valves. J Am Coll Cardiol. 1986;8: 41B-56.

9. Douglas PS, Hirshfeld JW Jr, Edie RN, Harken AH, Stephenson LW, Edmunds LH Jr. Clinical comparison of St. Jude and porcine aortic valve prostheses. Circulation. 1985;72:II135-9.

10. Hartz RS, Fisher EB, Finkelmeier B, DeBoer A, Sanders JH Jr, Moran JM, et al. An eight-year experience with porcine bioprosthetic cardiac valves. J Thorac Cardiovasc Surg. 1986;91:910-7.

11. Goldsmith I, Turpie AG, Lip GY. Valvar heart disease and prosthetic heart valves. Bmj. 2002;325:1228-31.

12. Mistiaen W, Van Cauwelaert P, Muylaert P, Sys SU, Harrisson F, Bortier H Thromboembolic events after aortic valve replacement in elderly patients with a Carpentier-Edwards Perimount pericardial bioprosthesis. J Thorac Cardiovasc Surg. 2004;127:1166-70.

13. Gherli T, Colli A, Fragnito C, Nicolini F, Borrello B, Saccani S, et al. Comparing warfarin with aspirin after biological aortic valve replacement: a prospective study. Circulation. 2004;110:496-500.

14. Babin-Ebell J, Schmidt W, Eigel P, Elert O. Aortic bioprosthesis without early anticoagulation-risk of thromboembolism. Thorac Cardiovasc Surg. 1995;43: 212-4.

15. Moinuddeen K, Quin J, Shaw R, Dewar M, Tellides G, Kopf G, et al. Anticoagulation is unnecessary after biological aortic valve replacement. Circulation. 1998; 98:II95-9.

16. Kalbfleisch P. The Statistical Analysis of Failure Time Data (Wiley Series in Probability and Statistics). Hoboken, NJ: John Wiley \& Sons; 1980.

17. Salem DN, Stein PD, Al-Ahmad A, Bussey HI, Horstkotte D, Miller N, et al. Antithrombotic therapy in valvular heart disease-native and prosthetic: the Seventh ACCP Conference on Antithrombotic and Thrombolytic Therapy. Chest. 2004; 126:457S-82S.

18. Orszulak TA, Schaff HV, Mullany CJ, Anderson BJ, Ilstrup DM, Puga FJ, et al. Risk of thromboembolism with the aortic Carpentier-Edwards bioprosthesis. Ann Thorac Surg. 1995;59:462-8.

19. Blair KL, Hatton AC, White WD, Smith LR, Lowe JE, Wolfe WG, et al. Comparison of anticoagulation regimens after Carpentier-Edwards aortic or mitral valve replacement. Circulation. 1994;90:II214-9.

20. Aramendi JL, Agredo J, Llorente A, Larrarte C, Pijoan J. Prevention of thromboembolism with ticlopidine shortly after valve repair or replacement with a bioprosthesis. J Heart Valve Dis. 1998;7:610-4.

21. Baumgartner HR. The role of blood flow in platelet adhesion, fibrin deposition, and formation of mural thrombi. Microvasc Res. 1973;5:167-79.

22. Virchow R. Cellular Pathology. London: Churchill; 1860.

23. Dumesnil JG, Pibarot P. Prosthesis-patient mismatch and clinical outcomes: the evidence continues to accumulate. J Thorac Cardiovasc Surg. 2006;131:952-5.

24. Blais C, Dumesnil JG, Baillot R, Simard S, Doyle D, Pibarot P. Impact of valve prosthesis-patient mismatch on short-term mortality after aortic valve replacement. Circulation. 2003;108:983-8.

25. Rao V, Jamieson WR, Ivanov J, Armstrong S, David TE. Prosthesis-patient mismatch affects survival after aortic valve replacement. Circulation. 2000;102: III5-9.

26. Tasca G, Brunelli F, Cirillo M, DallaTomba M, Mhagna Z, Troise G, et al. Impact of valve prosthesis-patient mismatch on left ventricular mass regression following aortic valve replacement. Ann Thorac Surg. 2005;79:505-10.

\section{Discussion}

Dr Steven W. Guyton, MD (Portland, Ore). We don't know if anticoagulation is beneficial in this group of patients, but we, as you noted, have seen that it doesn't cause dramatic increases in bleeding perioperatively. You noted the lack of appropriately powered randomized trials of postoperative anticoagulation. This again is a retrospective study and limited by selection bias, treatment bias, and confounding. There seems to be some confusion in the article in that you note that this confounding cannot be completely eradicated, but in the next sentence you say "we have eliminated confounders by further restrictions on the data." You tried to decrease the bias of this retrospective study by a propensity-based analysis, but one of your strongest conclusions is that $19-\mathrm{mm}$ valves are at higher risk, yet in your propensity analysis all the 19-mm valves dropped out. Can you try to explain that?

Dr Elbardissi. I'm not sure I understand your question, can you please rephrase it?

Dr Guyton. When I looked at your propensity analysis data sheet, the range of valve size was from 21 to $25 \mathrm{~mm}$. All the $19-$ $\mathrm{mm}$ valves were gone.

Dr Elbardissi. You are looking at the interquartile range. The 25 th percentile was the $21-\mathrm{mm}$ valve, and the 75 th percentile was the 25-mm valve.

Dr Guyton. I see, so it was not a range. It's an interquartile. All right. That was not clear from the data. Now your institutional practice during this study seems to have been determined by individual surgeons. Is that correct?

Dr Elbardissi. That is correct.

Dr Guyton. And yet you note that the majority do not anticoagulate with low-molecular-weight heparin, VKAs, or provide antiplatelet therapy, but $54 \%$ of your anticoagulation-negative patients were discharged on aspirin. It seems to me that more than half of them had anticoagulation or aspirin.

Dr Elbardissi. That's true. With regard to VKAs (warfarin specifically in this case), the majority of surgeons at our institution will not anticoagulate. As you saw from my first table, there are certain preoperative characteristics that would incline one to do so, primarily in patients who are thought to be at a relatively high risk of TE. The inclination not to provide some form of antiplatelet therapy is less pronounced. You are correct that approximately one half of the cohort was given aspirin, which is consistent with a more liberal practice pattern that we observed at our institution.

Dr Guyton. Some of the conclusive statements in the article are hidden in the body of the article where you say that VKAs or aspirin is not indicated for widespread use in BPAV implantation and widespread early anticoagulation offers minimal benefit. More than half of both of your categories of anticoagulation negative/anticoagulation positive were on aspirin and your final conclusion says postoperative antithrombotic therapy should be considered for female patients, patients with small aortic prostheses, and patients who are severely symptomatic preoperatively. It is a little unclear whether you are recommending anticoagulation or antithrombotic therapy.

Dr Elbardissi. The objective of our study was not to assess the best type of antithrombotic therapy (aspirin vs warfarin). That being said, it would have been easy to end our analysis by looking at the thromboembolic risk with regard to anticoagulation or antiplatelet therapy. We took it one step further, identified risk factors 
of TE, and then identified if providing some form of therapy was efficacious. Because our study was not designed to assess whether antiplatelet therapy or anticoagulation is more beneficial than the other, we leave it open to the readers to make that assertion on the basis of their interpretation of our data.

Dr Guyton. I agree with that. I think the important thing is that you potentially identified areas that require additional randomized trials to try and evaluate them.

Dr Thoralf Sundt, MD (Rochester, Minn). Drew, that was beautifully presented. For those in the audience who do not know, Drew was a Mayo medical student, and so we will proudly take credit for all of his subsequent success throughout his career. I appreciate you quoting me in your presentation because I intend to quote you later on this morning.

Can you give us an idea about what you think the mechanism is for this effect, the reduction in thromboembolic events, specifically in this subset of patients. I have my own thoughts, but I would be interested in yours first.

Dr Elbardissi. With regard to forming clot, the theory is that clot forms on the prosthetic sewing ring. As such, you want to anticoagulate or provide some form of antithrombotic therapy until endothelialization of the sewing ring occurs. That being said, why are we finding that certain subsets of patients have a higher risk of TE compared with the remainder of our cohort? I think this has to do with the small size of the valve and depressed left ventricular function. First, it is important to note that we only identified univariate predictors of TE, meaning that each predictor is not necessarily causally related to TE and may in fact demonstrate variability in the dataset that we cannot further characterize. According to my own rigorous analysis of the data and knowing how each of these predictors function, it is my theory that it comes down to the 19-mm valve and depressed left ventricular function. Why? We know from my previous laboratory studies that high laminar flow and decreased ejection fraction can both contribute to the incidence of thrombus formation.

Dr Sundt. I will give you an alternative hypothesis for what it's worth. I'll bet you a Coke in a bottle that what this really is a matter of silent postoperative atrial fibrillation. I think the markers you have looked at are markers of postoperative atrial fibrillation, and I'll bet it has nothing to do at all with endothelialization of the sewing ring of the valve. It is just postoperative atrial fibrillation, and the people who are at high risk for that, most of which is unrecognized, are those with silent atrial fibrillation, and those who are anticoagulated are protected. Of course I have no proof of that, but you might look at your left atrial size in your cohort or something like that as another predictor of atrial fibrillation. That is another thing to consider.

Dr Craig Baker, MD (Los Angeles, Calif). At our institution, we do not routinely anticoagulate bioprosthetic valves; we have seen 2 cases in the last couple years of very early bioprosthetic valve deterioration. It is difficult to describe, but it presents as aggressive calcium and platelet deposits. Dr Damiano's group described a similar phenomena a couple of years ago in 4 patients. I contacted him, and it is their practice not to anticoagulate patients either. I am curious in your extensive review of all your patients, did you have this phenomenon in your approximately $1000 \mathrm{pa}-$ tients? If you did, did you see it in anticoagulated or unanticoagulated patients?

Dr Elbardissi. That is not something that we initially looked for when reviewing these patients. It was not a hypothesis that I knew existed with regard to the causes of TE in this cohort of patients, but it is something interesting that we can certainly look at.

Dr Nimesh Desai, MD (Philadelphia, $\mathrm{Pa}$ ). One quick comment about the $19-\mathrm{mm}$ valve hypothesis. In our experience, and this is borne out in the literature, patients who receive 19-mm valves are just a different group of patients. They are older. They are female. They are sick. They have severe atherosclerosis. Their valves are tremendously calcified. Their roots are calcified. Their ascending aortas have calcium in them, as do their arches. Although there is certainly a scientific hypothesis that a smaller valve that has different flow characteristics may be more thrombogenic, these patients are at risk for stroke for any cardiac operation and are actually at elevated risk for stroke even if they didn't have heart surgery.

Dr Elbardissi. I appreciate that comment. If we only looked at the predictors of TE, I agree that it would be hard to endorse providing some form of antithrombotic therapy. However, we had enough variability in our practice patterns to evaluate whether either form of antithrombotic therapy was efficacious in this group. In fact, we saw a reduction in the incidence of TE in patients with $19-\mathrm{mm}$ valves. This indicates that regardless of the cause, we should at least be aware of the potential risk reduction that exists with antithrombotic therapy when implanting these valves and be aggressive by providing at least aspirin postoperatively.

Dr Desai. In your model did you correct for the presence of peripheral vascular disease or cerebrovascular disease?

Dr Elbardissi. Yes. Initially, anticoagulated patients had a higher incidence of peripheral vascular disease. After propensity adjustment, that was no longer significant. 